\title{
Time expenditure in computer aided time studies implemented for highly mechanized forest equipment
}

\author{
E. C. Mușat, A. I. Apăfăian, Gh. Ignea, V. D. Ciobanu, E. Iordache, R. Al. Derczeni, Gh. \\ Spârchez, M. M. Vasilescu, S. Al. Borz
}

Mușat E.C., Apăfăian A.I., Ignea Gh., Ciobanu V. D., Iordache E., Derczeni R. Al., Spârchez Ghe., Vasilescu M. M., Borz S. Al., 2016. Time expenditure in computer aided time studies implemented for highly mechanized forest equipment. Ann. For.

Res. 59(1): 129-144.

Abstract. Time studies represent important tools that are used in forest operations research to produce empirical models or to comparatively assess the performance of two or more operational alternatives with the general aim to predict the performance of operational behavior, choose the most adequate equipment or eliminate the useless time. There is a long tradition in collecting the needed data in a traditional fashion, but this approach has its limitations, and it is likely that in the future the use of professional software would be extended is such preoccupations as this kind of tools have been already implemented. However, little to no information is available in what concerns the performance of data analyzing tasks when using purpose-built professional time studying software in such research preoccupations, while the resources needed to conduct time studies, including here the time may be quite intensive. Our study aimed to model the relations between the variation of time needed to analyze the video-recorded time study data and the variation of some measured independent variables for a complex organization of a work cycle. The results of our study indicate that the number of work elements which were separated within a work cycle as well as the delay-free cycle time and the software functionalities that were used during data analysis, significantly affected the time expenditure needed to analyze the data $(\alpha=0.01, p<0.01)$. Under the conditions of this study, where the average duration of a work cycle was of about 48 seconds and the number of separated work elements was of about 14, the speed that was used to replay the video files significantly affected the mean time expenditure which averaged about 273 seconds for half of the real speed and about 192 seconds for an analyzing speed that equaled the real speed. We argue that different study designs as well as the parameters used within the software are likely to produce different results, a fact that should trigger other studies based on variations of these parameters. However, the results of this study give an initial overview on the time resources needed in processing and analyzing the data, and may help researchers in allocating their resources. 
Keywords AviX, purpose-designed industrial time studying software, dependence, analyzing and processing time, complexity, computer-aided time studies

Authors. Elena Camelia Mușat, Andrei Ioan Apăfăian, Gheorghe Ignea, Valentina Doina Ciobanu, Eugen Iordache, Rudolf Alexandru Derczeni, Maria Magdalena Vasilescu, Stelian Alexandru Borz (stelian.borz@unitbv.ro) - Transilvania University of Braşov, Faculty of Silviculture and Forest Engineering, Department of Forest Engineering, Forest Management Planning and Terrestrial Measurements, Şirul Beethoven, no. 1, 500123, Braşov; Gheorghe Spârchez - Transilvania University of Braşov, Faculty of Silviculture and Forest Engineering, Department of Silviculture, Şirul Beethoven, no. 1, 500123, Braşov.

Manuscript received June 10, 2015; revised September 12, 2015; accepted September 20, 2015; online first November 24, 2015.

\section{Introduction}

In the near future, one of the major challenges in forest operations management will be to develop mathematical tools aiming to support the distributed and coordinated decision making (Heinimann 2007). At the same time, as a scientific discipline, the forest operations management deals a lot with the analysis, design, control and continuous improvement of business processes (Heinimann 2007). Essentially, forest operations are cost driven activities (Oprea \& Borz 2007) and require substantial resources for their fulfillment. Time inputs for effectively carrying out forest operations as well as time needed to collect, process and analyze data needed for their performance modeling constitute important resources in forest operations management. Ever since the emergence of industrial engineering, the time studies whose father is considered to be Frederick Wilson Tyler (Heinimann 2007) were used to systematically study the work processes; this concept entered forestry after 1900 (Heinimann 2007) where they evolved accordingly, by adaptation to the specificity of forest work processes (Björheden et al. 1995). Time studies are particularly needed when the performance metrics of a given harvesting equipment or system are under the investigation. Furthermore, time modeling studies are useful in producing empirical models that have the capability to predict the performance of harvesting equipment under given operational conditions 130
(Visser \& Spinelli 2012) but, depending on their intended scope and accuracy, they may require substantial resources (Magagnotti \& Spinelli 2012), including time. In a broader sense, in forest operations management a time study aims to quantify, classify, systematically and critically analyze the time inputs in order to relate them, one way or another, to operational variables or work conditions (Magagnotti \& Spinelli 2012) or to eliminate the useless time (Björheden et al. 1995) with the purpose to increase the operational efficiency.

Accordingly, time studies may be carried out by using traditional or more or less advanced tools and techniques. Video capturing has the advantage to fully collect the real sequence in operations enabling this way data rechecking when needed and elimination of delays, but it needs additional analysis in order to extract the elemental time expenditures. Furthermore, by finding and setting an adequate position to install the recording device, one can exclude the delays that otherwise may be induced by the researcher presence and interventions in the usual way of work (Magagnotti \& Spinelli 2012). On the other hand, the traditionally conducted studies may enable the use of snapback chronometry, a technique that allows the direct measurement of time expenditure on work elements (Björheden et al. 1995). However, this approach needs additional time to transfer the data usually collected on paper sheets into computer software that enables the data processing and analysis. 
In timber harvesting engineering, one of the future challenges will be to disseminate and apply the knowledge of advanced, highly-mechanized harvesting technologies in developing countries (Heinimann 2007) and the highly-mechanized harvesting technologies include forest equipment such as harvesters (Oprea 2008). At the same time, substantial differences between regions in terms of forest conditions and management procedures would be likely to trigger regional time studies on highly-mechanized forest equipment since the presence of significantly contrasting working conditions may affect the outcomes of a study and the results reported in some regions may not be extensively used in a given particular region (Hiesl \& Benjamin 2014). On the other hand, when conducting time studies on highly-mechanized forest equipment, the duration of some given work elements may be very short while their number can be quite increased. For instance, harvesters and processors have capability to fell and (or) process trees, and studies that assessed their performance generally re ported an increased number of work elements, out of which the tree felling cuts (Acuna et al. 2011) as well as the crosscuts performed in order to recover the wood assortments from the felled trees (Borz et al. 2014) are known to be very short duration work elements. Also, in the case of more complex machines such as harwarders, the sequence and the number of work elements may be very complex and increased respectively, exceeding in some cases 15 work elements (Anderson \& Eliasson 2004), facts that complicate the measurements in traditional approaches and which will probably lead, in the near future, to the a generalization in use of video capturing or other alternative data collection techniques. On the other hand, researching procedures coupled with video capturing time studies may be resource intensive, because the video files have to be replayed and critically analyzed. An improved time management is likely to be obtained by using purpose designed industrial video time study software, as this approach has already been implemented in forest operations research (Acuna et al. 2011, Alam et al. 2013). Alternatively, the video files analysis using some tools that are programmatically developed to provide similar time studying functionalities may be successfully employed to conduct time studies in forest operations (Niemisto et al. 2012). While the capabilities and functionalities of industrial time study software may be quite well known, the relation between time needed to process and analyze the data and the complexity of such tasks is less understood, even if the experience with such software increased lately in forest operations time studies. Also, the reporting of time spent for collecting the necessary data from the field within the study itself became almost a standard in time studies, given the fact that persons interested in such results may appreciate the study extent based on this figure. However, the extent of time needed to process and analyze the data using professional time studying software is not known as we reviewed a number of recent studies that were shaped around time studies carried out on highly-mechanized forest equipment such as feller-bunchers, harvesters, harwarders and processors. In this context, the aim of this study was to relate the complexity of data processing and analyzing tasks to time expenditure involved by such tasks when using industrial time studying software to analyze video collected data for a harvester. The objectives of the study were to: (i) examine and model the time expenditure for two replaying speeds as well as for an entire extensive data pool relative to some independent variables describing the task complexity, (ii) develop descriptive statistics that could help in differentiating between different statistical treatments shaped around the video replaying speed and (iii) calculate the performance metrics for data processing and analysis tasks as being specific to this study. 


\section{Material and methods}

\section{Study design}

Clear cut operations were carried out in the summer of 2014 in a dried-out Norway spruce (Picea abies (L.) Karst) stand located in the proximity of Cristeşti, Iaşi County, Romania. Harvest information indicated an average breast diameter of $23 \mathrm{~cm}$, an average tree height of $18.5 \mathrm{~m}$ and an average tree volume of $0.364 \mathrm{~m}^{3}$. In Romania both, natural and cultivated areal of the Norway spruce cover about 1.43 million hectares (Şofletea \& Curtu 2008) and the artificial spruce stands that were cultivated outside their natural areal are quite common due to the silviculture trends practiced in the past. However, these practices resulted in less stable stands that were frequently affected by windthrows, tree breakage and tree-drought, and there is an increased need to replace them by using locally available natural species. A Valmet 911.4 harvester was used to fell and process the trees as well as to pile the logs and a Komatsu 840.4 forwarder was used to extract the wood to the roadside, in the commonly known cut-to-length harvesting method. Both machines were manufactured in 2010. While the field data was collected using different techniques and logistics for both machines, only the harvester's operations were video recorded and used in this study. The video files were collected using a digital camera that was set to continuously record durations of one hour in length each. The camera was placed in the harvester cab in a position that allowed a good visibility, and the operator of the machine was asked to restart the video recording after each of its stops. The field study was carried out for a number of 15 work days (47.5 effectively recorded hours), and the resulted video files were downloaded into a PC at the end of each day. A part of the resulted video files (corresponding to 6 field collection data days respectively 28 hours) were used as inputs for a detailed computer aided time anal- ysis. The AviX (v.4.6.1.) trial version software was used to import and analyze the video files as well as to export the resulted data into $\mathrm{M}$. Excel spreadsheets. This kind of software is characterized by several capabilities and functionalities, allowing the video files replaying at different preset speeds as well as the precise delimitation of the chosen work elements and computation of descriptive statistics that are specific to the conducted studies. This software was developed by Solme AB (Sweden) and it was intended for industrial work measurement applications.

The typical work organization, as it was observed in the field, consisted of the straight ahead frontal machine movement along a strip to be harvested, stops, boom movement to reach the trees to be felled and processed, tree securing, felling cut, lateral movement of the loaded boom to the assortments piles and tree processing. An analyzed work cycle was structured as presented in Equation 1. The full description of the identified and delimited work elements is given in Table 1. Tree processing has been carried out in order to obtain 3 and 4 meters in length wood assortments. Therefore, the processing operations needed several crosscuts as well as one or more rolling of the processing head along each processed log. In this respect, the computer aided time analysis was focused on each tree and a full tree felling and processing cycle time has been designed and analyzed according to the Equation 2. A full description of the time elements is also given in Table 1.

$T F P=M M T+S F T+T S+T C+S P T+T P+$ $R H+P T T$

$T F P t=M M T t+S F T t+T S t+T C t+S P T t+T P t$

+ RHt + PTTt

Two workers, having quite different operational experiences, operated the same machine during the field operations. For performance analysis purposes that are not presented here- 
Table 1 Description of the elemental work and time elements

\begin{tabular}{|c|c|c|}
\hline Denomination & Abbreviation & Description \\
\hline $\begin{array}{l}\text { Tree felling and } \\
\text { processing }\end{array}$ & TFP & TFP - Sum of the following work elements \\
\hline \multirow{2}{*}{ Moving to tree } & MT & $\begin{array}{l}\text { MT - Machine moving in a straight line between successive tree } \\
\text { groups to be felled and processed. Repeated for a number of }\end{array}$ \\
\hline & MTt & $\begin{array}{l}\text { MTt - The time needed for machine moving between successive } \\
\text { tree groups to be felled and processed }\end{array}$ \\
\hline \multirow{2}{*}{$\begin{array}{l}\text { Swinging to fell the } \\
\text { tree }\end{array}$} & SFT & $\begin{array}{l}\text { SFT - Machine slewing and extending the boom to position the } \\
\text { felling head on a tree to be felled. Repeated for almost each } \\
\text { tree. }\end{array}$ \\
\hline & SFTt & $\begin{array}{l}\text { SFTt - The time needed to slew and extend the machine's boom } \\
\text { to the tree to be felled. }\end{array}$ \\
\hline \multirow[t]{2}{*}{ Tree securing } & TS & $\begin{array}{l}\text { TS - Grabbing the tree to be felled in the felling head. Repeated } \\
\text { for almost each tree. }\end{array}$ \\
\hline & TSt & TSt - The time need to secure the tree in the felling head. \\
\hline \multirow[t]{2}{*}{ Tree cutting } & $\mathrm{TC}$ & $\begin{array}{l}\text { TC - Operating the saw to fell the tree. Repeated for almost } \\
\text { each tree. }\end{array}$ \\
\hline & $\mathrm{TCt}$ & TCt - The time needed to perform the felling cut. \\
\hline \multirow{2}{*}{$\begin{array}{l}\text { Swinging to process } \\
\text { the tree }\end{array}$} & SPT & $\begin{array}{l}\text { SPT - Slewing the felled tree and lower to the ground over the } \\
\text { assortments pile. Repeated for each tree. }\end{array}$ \\
\hline & SPTt & $\begin{array}{l}\text { SPTt - the time needed to slew and lower the tree to the ground } \\
\text { over the assortment pile. }\end{array}$ \\
\hline \multirow{2}{*}{ Tree processing } & TP & $\begin{array}{l}\text { TP - Rolling the head along the tree in order to delimb and } \\
\text { crosscut. Repeated for each tree. Further divided at log-level. }\end{array}$ \\
\hline & $\mathrm{TPt}$ & TPt - The time needed to process (delimb and crosscut) the tree. \\
\hline \multirow{2}{*}{$\begin{array}{l}\text { Recalibrating the } \\
\text { head }\end{array}$} & RH & $\begin{array}{l}\text { RH - Repositioning the head for measurement recalibration } \\
\text { purposes. Repeated for a small number of trees. }\end{array}$ \\
\hline & RHt & $\mathrm{RHt}$ - The time needed to recalibrate the measuring system. \\
\hline \multirow{2}{*}{$\begin{array}{l}\text { Processing the tree } \\
\text { top }\end{array}$} & PTT & $\begin{array}{l}\text { PTT - Moving and crosscutting the top over a branch pile. } \\
\text { Repeated for almost each tree. }\end{array}$ \\
\hline & PTTt & PTTt - The time needed for tree top moving and crosscutting. \\
\hline
\end{tabular}

in, the tree processing time was further divided and analyzed at the level of each processed log, a fact that supposed a substantial increment in the number of work elements and which also led to additional interactions between the researcher who analyzed the data and the software used respectively. In order to enable the software's time separation and categorization functionalities, each of the work elements needed a code to be assigned each time a work element was separated. While the software supports, basically, any coding type, for practical reasons we used a one digit-based code to sequentially differentiate between the elemental time consumptions. Also, in order to assess the effect that the video replaying speed may have on the time needed for data analysis (TEAt), a number of 402 work cycles were 
analyzed using half of the real speed while the rest of the data (793 work cycles) was analyzed at the real speed.

The computer aided data analyzing time (TEAt) was collected for each analyzed work cycle as the latter was described in Equation 1 and Table 1, by implementing a self quantification of the time expenditure at work cycle level using a professional stopwatch. Values of the TEAt were collected by using an accuracy of one second, and they were cycle-wise noted separately on paper. At the end of each work session and following the data exporting into M. Excel, the TEAt values were transcribed in the datasheets for each of the analyzed work cycles. A number of 28 hours of video recording were considered in this study, meaning that the number of analyzed video files equaled the number of analyzed hours. The time needed to setup a work session (TS) as well as the time needed to export the data (TE) following a full one-hour video file analysis were measured for each of the analyzed video files by using the same procedures as described above. In this respect, the procedures used to setup and export the data were the same for each of the analyzed video files and we assumed in our study that $T S$ and $T E$ were not directly related to any quantifiable variable that could be measured during or following the video time analysis. Then, the exported data needed some reconversions, which were performed on the whole fully processed dataset and which were considered outside of this study scope.

The complexity of the socio-technical systems is difficult to measure. Schöttl \& Lindemann (2015) argued that in order to derive values of the perceived complexity, as the latter is specific to any particular system, one has to multiply the values designating the complexity potential, interaction type and the perception, where the complexity potential of a system consists of the system properties (e.g. number of components) and their dynamics, the interaction type represents the interaction properties and the perception refers to the perception of a person in terms of experience and mental flexibility. In essence, a work cycle as described in this study was considered to be a technical system, being characterized by a complexity that varied cycle-wise from one instance to another as a function of the sequence and number of contained work elements. Since the precise sequencing of work elements was rather difficult to measure in order to derive a complexity metric, and the work pattern, therefore the work elements sequence did not significantly varied from one work cycle to another, in this study we used the cycle-wise number of work elements $(N W E)$ as a measure of the system size since their number clearly affects the time consumption in tree felling and processing operations and, following a given proportionality, it may affect also the time consumption in data analyzing activities. Furthermore, the empirical models that can be derived from such an approach could be more useful for practical purposes. However, in order to accommodate the variability that otherwise could arise from the different cycle-wise sequencing or from other reasons including the duration of each work cycle, we used also the tree felling and processing time (TFPt) as an independent variable for modeling purposes. Therefore, the number of work elements (NWE) within each of the analyzed work cycles, the tree felling and processing time (TFPt) as it resulted from data analysis, as well as the speed of replaying $(S R)$ the video files were used as independent variables, since the number of interactions between the user and the software (i.e. the number of clicks) were numerically and sequentially equivalent for each of the work elements analyzed within a work cycle. On the other hand, some of the analyzed work cycles needed additional commenting tasks which supposed additional time consumption. Given the fact that there were few cases that needed this treatment, commenting during the analysis was not considered as a potential explaining variable, and its effects were included in the total variability of the TEAt. The same proce- 
dure was used also for a small number of cases in which the replaying speed had to be reduced in order to facilitate the analysis of some of the work elements.

\section{Experimental design and statistical analysis}

Two experimental treatments were separated from the general data pool. One of them in-

Table 2 Description of the elemental work and time elements

\begin{tabular}{|c|c|c|c|c|c|c|c|}
\hline $\begin{array}{l}\text { Variable name and } \\
\text { measurement unit }\end{array}$ & $\begin{array}{l}\text { Experimental } \\
\text { treatment }\end{array}$ & $\mathrm{N}$ & Min. & Max. & Range & Mean & St. dev. \\
\hline \multirow{3}{*}{ MMTt (seconds) } & ET1 & 83 & 4.40 & 32.70 & 28.30 & 12.94 & \pm 5.26 \\
\hline & ET2 & 187 & 4.76 & 41.20 & 36.50 & 14.09 & \pm 5.03 \\
\hline & GET & 270 & 4.40 & 41.20 & 36.80 & 13.73 & \pm 5.12 \\
\hline \multirow[t]{3}{*}{ SFTt (seconds) } & ET1 & 367 & 1.40 & 23.80 & 22.40 & 5.13 & \pm 2.38 \\
\hline & ET2 & 712 & 1.00 & 27.00 & 26.00 & 5.71 & \pm 3.02 \\
\hline & GET & 1079 & 1.00 & 27.00 & 26.00 & 5.51 & \pm 2.83 \\
\hline \multirow[t]{3}{*}{ TSt (seconds) } & ET1 & 398 & 0.20 & 21.00 & 20.80 & 4.48 & \pm 2.08 \\
\hline & ET2 & 785 & 0.60 & 17.20 & 16.60 & 4.45 & \pm 1.99 \\
\hline & GET & 1183 & 0.20 & 21.00 & 20.80 & 4.46 & \pm 2.02 \\
\hline \multirow[t]{3}{*}{ TCt (seconds) } & ET1 & 399 & 0.30 & 14.40 & 14.10 & 2.24 & \pm 1.68 \\
\hline & ET2 & 787 & 0.40 & 20.60 & 20.20 & 2.03 & \pm 1.48 \\
\hline & GET & 1186 & 0.30 & 20.60 & 20.30 & 2.10 & \pm 1.55 \\
\hline \multirow[t]{3}{*}{ SPTt (seconds) } & ET1 & 395 & 2.00 & 33.80 & 31.80 & 4.87 & \pm 2.81 \\
\hline & ET2 & 782 & 0.10 & 69.00 & 68.90 & 5.68 & \pm 4.37 \\
\hline & GET & 1177 & 0.10 & 69.00 & 68.90 & 5.41 & \pm 3.94 \\
\hline \multirow[t]{3}{*}{ TPt (seconds) } & ET1 & 402 & 3.50 & 64.30 & 60.80 & 25.62 & \pm 9.18 \\
\hline & ET2 & 793 & 2.70 & 126.40 & 123.70 & 23.18 & \pm 9.61 \\
\hline & GET & 1195 & 2.70 & 126.40 & 123.70 & 24.00 & \pm 9.53 \\
\hline \multirow[t]{3}{*}{ Tbrt (seconds) } & ET1 & 402 & 3.20 & 59.10 & 55.90 & 22.20 & \pm 8.50 \\
\hline & ET2 & 793 & 2.50 & 123.40 & 120.90 & 20.28 & \pm 9.01 \\
\hline & GET & 1195 & 2.50 & 123.40 & 120.90 & 20.92 & \pm 8.88 \\
\hline \multirow[t]{3}{*}{ Tcct (seconds) } & ET1 & 402 & 0.10 & 12.80 & 12.70 & 3.42 & \pm 1.49 \\
\hline & ET2 & 793 & 0.20 & 11.50 & 11.30 & 2.90 & \pm 1.31 \\
\hline & GET & 1195 & 0.10 & 12.80 & 12.70 & 3.07 & \pm 1.39 \\
\hline \multirow[t]{3}{*}{ PTTt (seconds) } & ET1 & 398 & 0.90 & 22.10 & 21.20 & 4.01 & \pm 2.16 \\
\hline & ET2 & 783 & 0.50 & 19.70 & 19.20 & 4.45 & \pm 2.38 \\
\hline & GET & 1881 & 0.50 & 22.10 & 21.60 & 4.30 & \pm 2.32 \\
\hline \multirow[t]{3}{*}{ RHt (seconds) } & ET1 & 32 & 0.60 & 3.40 & 2.80 & 1.22 & \pm 0.76 \\
\hline & ET2 & 39 & 0.40 & 13.00 & 12.60 & 2.63 & \pm 2.93 \\
\hline & GET & 71 & 0.40 & 13.00 & 12.60 & 1.99 & \pm 2.33 \\
\hline \multirow[t]{3}{*}{ TFPt (seconds) } & ET1 & 402 & 20.00 & 96.00 & 76.00 & 48.48 & \pm 12.25 \\
\hline & ET2 & 793 & 13.50 & 143.20 & 129.70 & 48.17 & \pm 15.49 \\
\hline & GET & 1195 & 13.50 & 143.20 & 129.70 & 48.28 & \pm 14.47 \\
\hline \multirow[t]{3}{*}{ NWE } & ET1 & 402 & 6.00 & 21.00 & 15.00 & 14.19 & \pm 1.81 \\
\hline & ET2 & 793 & 7.00 & 18.00 & 11.00 & 13.62 & \pm 1.86 \\
\hline & GET & 1195 & 6.00 & 21.00 & 15.00 & 13.81 & \pm 1.86 \\
\hline \multirow[t]{3}{*}{ TEAt (seconds) } & ET1 & 402 & 119.0 & 500.00 & 381.00 & 272.53 & \pm 66.77 \\
\hline & ET2 & 793 & 89.00 & 462.00 & 373.00 & 191.82 & \pm 44.36 \\
\hline & GET & 1195 & 89.00 & 500.00 & 411.00 & 218.97 & \pm 65.25 \\
\hline
\end{tabular}


cluded only the data that was analyzed at half of the real speed $(E T 1, N=402)$ while the other one, that was analyzed at the real speed, used the remaining data $(E T 2, N=793)$. The used statistical procedures and techniques were adapted to the specific of general concepts that are usually employed in time studies (Magagnotti \& Spinelli 2012). Descriptive statistics (Table 2) were computed for all the variables included in the two considered treatments, as well as for the global data pool that was regarded as a third treatment $(G E T)$. Separate regression models were computed for each of the first two experimental treatments, by using as a response variable the time expenditure involved by the data analysis $\left(T E A t_{E T T}, T E A t_{E T 2}\right)$.

For each of the modeled equations we used as independent variables the number of work elements $\left(N W E_{E T 1}, N W E_{E T 2}\right)$ that were separated for each of the analyzed work cycles as well as the tree felling and processing time (TFP$\left.t_{E T T}, T F P t_{E T 2}\right)$ as it resulted from the analysis. Before actually using the two sets of data, a correlation analysis was carried out in order to determine whether the association between the two variables would be likely to artificially increase the determination coefficients in the resulted models. The global significance of the resulted models, as well as the significance of each of the used independent variables were tested by considering a confidence threshold of $\alpha=0.01(p<0.01)$. Finally, a global regression model explaining the cycle-wise time expenditure needed to analyze the data $\left(T E A t_{G E T}\right)$ was computed for all the data used in the study, by including also the replaying speed $(R S)$ as a dummy (indicator) variable. For this purpose, in the regression analysis we used binary values for the two speeds, by attributing a zero value to the $R S$ in the second treatment and a value equaling 1 for the $R S$ variable in the first treatment, assuming that the time needed to analyze the data would be significantly greater in the first treatment. This model was developed in order to include the effect of the replaying speed $(R S)$ in the variation of TEAt, a fact that enables comparisons and may help research practitioners in assessing their time resources.

Separate descriptive statistics were computed for the variables $T S$ and $T E(N=28)$. Then, their mean values were divided by the mean number of work cycles analyzed within one hour in order to determine their mean contribution within the time expenditure for an analyzed work cycle. The resulting values were used to compute a global time expenditure model to be used in the assessment of effective time needed to fully setup, analyze and export the data (TSAE). This last model was developed by adding the fixed time expenditure as it resulted from the above procedures to the $T E A t_{G E T}$ variable prior to the TSAE model estimation.

Following the applicability of regression through origin examples given in Eisenhauer (2003) and by assuming that the inexistence of any work elements (NWE) would yield a zero value for the TFPt, therefore a duration equaling zero for a given analyzed video file, the regression through origin (RTO) technique was used as a general methodological approach in developing most of the models. However, we assumed that the loading of a video file into the used software would require its existence, therefore it will require the setup and subsequent data exporting time. For these reasons we used a fixed part (intercept) in the case of the final model that was developed in order to predict the TSAE variable.

The efficiency indicators related to the setting up, analyzing and exporting the data were separately calculated for each of the two treatments as well as for the global data pool by using the general procedures specific to any efficiency study, following the prescriptions described in Magagnotti \& Spinelli (2012) and in Björheden et al. (1995) respectively. In this manner, the efficiency $\left(E_{E T 1}, E_{E T 2}, E_{G E T}\right)$ was regarded as the effectively needed time to setup, analyze and export the data for one analyzed work cycle, the latter being considered as a 
work unit. While we fully acknowledge the functionality of many software products that can be used in statistical analysis of the time studying data (Magagnotti \& Spinelli 2012), we chose to use in our study the M. Excel 2007 software, as it enabled all the needed calculations and statistical analyses.

\section{Results}

\section{Descriptive statistics of the analyzed treat- ments}

Based on a self-assessment of the researcher who analyzed the data, the total duration of the office part of the study, including necessary breaks as well as other delays not related to the job tasks, was 30 days by assuming that a work day consisted of 8 hours allocated for work. Following the data analysis, 270 machine movements were required in order to fell and process 1195 trees (Table 2), meaning that on each machine movement a mean number of 4.43 trees were felled and processed. As shown in Table 2, some of the work elements did not occurred in each of the analyzed work cycles. However, the number of separate work elements varied widely between 6 and 21 per one analyzed work cycle. 5169 logs were recovered from the felled and processed trees, out of which a number of $1812 \operatorname{logs}$ were re-

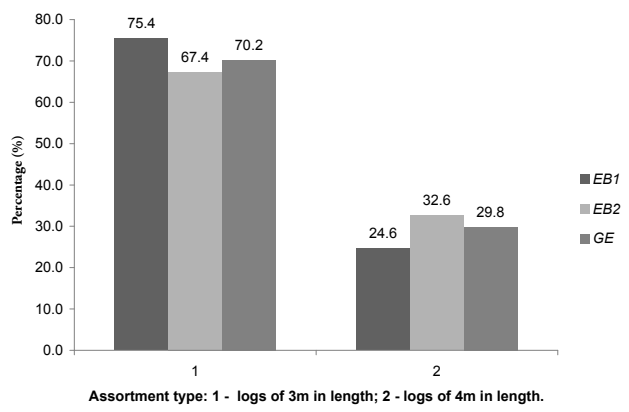

Figure 1 Shares of the 3 and 4 meter in length processed logs in the studied treatments covered within the ET1 and $3357 \operatorname{logs}$ were recovered in the ET2. The percentual distribution of the recovered logs on processing length classes is given in Figure 1.

As shown, there were some differences between the ET1 and ET2 in what concerns the number of recovered 3 and 4 meter in length logs. Furthermore, at the level of global data pool, the 3 meter in length logs were predominant, representing about $70 \%$ of the to tal recovered logs (Figure 1). The differences shown in Figure 1 were expected to produce significant differences in the time needed to process the trees. As shown in Table 2, the time consumption differences were rather small between the ET1 and ET2 in what concerns the time spent to crosscut the trees. On the other hand, average time spent to debranch the trees was 1.92 seconds in ET1. Also, the average time spent to process the trees (TPt) was 2.44 seconds longer in ET1 if compared with ET2. Altogether, the tree felling and processing time (TFPt) did not differed greatly between ET1, ET2 and GET (Table 2), averaging in all of the cases about 48 seconds. Coupled with a reduced replaying speed, the longer duration of TFPt in ET1 probably contributed to the increment of time spent to analyze and process the data as shown in Figure 2 and Table 2. The difference found between the two mentioned treatments was the result and may be explained by the two different replaying speeds. As a fact,

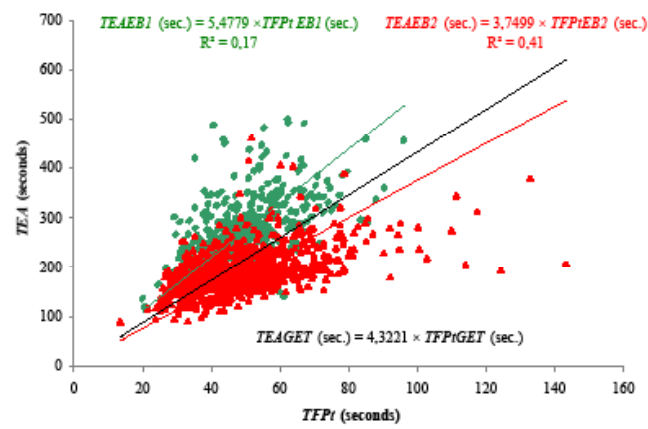

Figure 2 Dependence between the time needed to analyze the data (TEAt) and the tree felling and processing time $(T F P t)$ in the studied treatments 
for quite similar conditions in what regards the tree felling and processing time as well as for almost the same number of work elements in ET1 and ET2 (Table 2) the average time needed for analyzing a work cycle was almost 1.5 times greater in ET1, if compared to ET2. Furthermore, the mean time needed to analyze a work cycle in ET1 was almost 6 times greater than the average duration of an analyzed work cycle. By comparison, in ET2 the time needed for the same procedures was, in average, about 4 times greater than the effective mean duration of a work cycle (Table 2).

Following the calculation of separate descriptive statistics for $T S$ and $T E$ variables, the time needed for setting up a work session (TS) averaged $35.08 \pm 5.34$ seconds, ranging from 26.80 to 46.50 seconds $(N=28)$. On the other hand, it seems that the data exporting after the tasks completion for each of the analyzed video files needed, in average, more time. According to the conditions described in this study, $T E$ averaged $38.90 \pm 4.92$ seconds, ranging from 30.90 to 49.50 seconds. However, these figures refer to hourly-level analyzed video files. In conditions in which the total number of analyzed work cycles was of 1195 (Table 2) and the total number of analyzed hours was of 28 , the average number of analyzed work cycles per one hour of video recording was of 42.7, a fact that naturally led to $T S$ and $T E$ mean values of 0.82 respectively 0.91 seconds per work cycle.

\section{Time consumption prediction models}

The dependence relations between the tree felling and processing time (TFPt) and the time effectively needed (TEAt) to analyze the cycle-level data using the AviX software are given in Figure 2. As shown, the solely variation of the TFPt variable data pools could not fully explain the variation in the TEAt data pools. As a fact, only $17 \%\left(R^{2}=0.17\right)$ of the $T E A t_{E T 1}$ variation was explained by the variation of $T F P t_{E T 1}$ and only $41 \%\left(R^{2}=0.41\right)$ of the $T E A t_{E T 2}$ varia- tion was explained by the variation of $T F P t_{E T 2}$.

Assuming that the time needed to effectively analyze the data would be zero when the tree felling and processing time would equal zero, the equations shown in Figure 2 were fitted by accepting a zero value for the intercept. Following the correlation analysis, we found no strong associations between the independent variables NWE and TFPt. As a fact, the correlation coefficients yielded values of 0.57 , 0.45 and 0.48 for ET1, ET2 and GET respectively, a fact that enabled the computation of dependence between the responses in TEAt as a function of the TFPt and NWE (ET1 and ET2) respectively TFPt, NWE and RS (GET), using the $R T O$ procedures. The resulted models are enclosed in Table 3. As shown, the explaining capability of the used independent variables seemed to be substantially improved. However, the presented outputs are likely to be the results of the computational algorithm that is specific to RTO (Eisenhauer 2003), since the determination coefficient of the TSAE model (that was computed using ordinary least-squares regression), even improved, did not exceeded 0.60. All the developed models were very significant at the chosen confidence threshold, a fact that was also true in the case of the used independent variables. While all of the computed coefficients indicated significant magnitudes on the variation of time needed to analyze the data (ET1, ET2, GET), a replaying speed equaling half of the real one may add, in average, about 74 seconds when analyzing the data (Table 3).

Efficiency of the setup, analyzing and data exporting tasks. The self time management which is specific to different persons may affect the time consumption related to data analysis in computer aided time studies, giving different proportions of the effectively used time relative to the time allocated for work. In this study, the researcher who analyzed the time data by using the time studying software had an allocated work time totaling 240 hours (30 days) in which were analyzed 
Table 3 Time expenditure models for the computer-aided time study data analysis

\begin{tabular}{|c|c|c|c|c|c|c|}
\hline Estimated models & $N$ & $\begin{array}{l}R^{2} \\
a d j\end{array}$ & $F$ & Sign. $F$ & Predictors & $p$ value \\
\hline $\begin{array}{l}T E A t_{E T I}(\mathrm{sec} .)=10.811 \times N W E_{E T I}+ \\
2.449 \times T F P t_{E T I}(\mathrm{sec} .)\end{array}$ & 402 & 0.96 & 5584.93 & $<0.0001$ & $\begin{array}{l}\text { TFPt } \\
\text { NWE1 } \\
\text { NWE1 }\end{array}$ & $\begin{array}{l}<0.0001 \\
<0.0001\end{array}$ \\
\hline $\begin{array}{l}T E A t_{E T 2}(\mathrm{sec} .)=10.847 \times N W E_{E T 2}+ \\
0.915 \times T F P t_{E T 2}(\mathrm{sec} .)\end{array}$ & 793 & 0.97 & 13654.66 & $<0.0001$ & $\begin{array}{l}T F P t_{E T 2} \\
N W E 2\end{array}$ & $\begin{array}{l}<0.0001 \\
<0.0001\end{array}$ \\
\hline $\begin{array}{l}T E A t_{G E T}(\mathrm{sec} .)=9.691 \times N W E_{G E T}+ \\
1.251 \times T F P t_{G E T}(\mathrm{sec} .)+74.372 \times R S^{*}\end{array}$ & 1195 & 0.97 & 11672.90 & $<0.0001$ & $\begin{array}{l}T F P t_{G E T} \\
N W E \\
R S\end{array}$ & $\begin{array}{l}<0.0001 \\
<0.0001 \\
<0.0001\end{array}$ \\
\hline $\begin{array}{l}T S A E(\mathrm{sec} .)=11.047 \times N W E_{G E T}+ \\
1.245 \times T F P t_{G E T}(\mathrm{sec} .)+74.110 \times \\
R S^{*}-16.927\end{array}$ & 1195 & 0.60 & 589.37 & $<0.0001$ & $\begin{array}{l}\text { TFPt } \\
\text { NWE } \\
R S\end{array}$ & $\begin{array}{l}<0.0001 \\
<0.0001 \\
<0.0001\end{array}$ \\
\hline
\end{tabular}

Note.* $R S=0$ in $E T 2$ and $R S=1$ in $E T 1$

28 hours of video recordings. In addition, 5 hours were used to collect figures about the time needed to setup and export the data for each of the 28 hours taken into study. The increased amount of time needed to analyze the data may be explained by the highly demanding tasks that needed intensive focusing of the researcher attention on the accurate separation of the work elements since their number was rather increased in this study. Also, part of the allocated time was used to write the results of self-evaluation on paper. However, following the calculations, the time effectively needed to fully setup, analyze and export the data differed significantly between the treatments. For instance, the efficiency assessment in case of ET1 $\left(E_{E T I}\right)$ yielded a mean value of $274.26 \mathrm{sec}-$ onds $\times$ work cycle ${ }^{-1}$, indicating that the time resources needed were significantly greater if compared with those corresponding to ET2 $\left(E_{E T 2}=193.55\right.$ seconds $\times$ work cycle $\left.{ }^{-1}\right)$. Also, at the global level, the $E_{G E T}$ yielded a net value of 220.70 seconds $\times$ work cycle ${ }^{-1}$. Therefore, for fully processing and analyzing a work cycle, there were required about $0.08,0.05$ and 0.06 hours in conditions of ET1, ET2 and GET respectively.

\section{Discussion}

Data processing tasks in computer-aided time studies may require important time resources. The results of this study indicate that there are dependence relations that can be statistically shown between the time needed to process the data and given variables. In this study, the duration of a work cycle affected the time needed to process the data irrespective of the used speed and the number of work elements within a work cycle. As a fact, the effect of work cycle duration was greater when trying to explain the variation of time needed to process the data in ET1 as shown by the regression coefficient of $T F P t_{E T I}$, and less (almost half) in the case of ET2. However, the number of work elements had relatively the same effect of magnitude irrespective of the developed model, and they contributed significantly to the explanation of $T E A t$, given the number of work elements in this study. The results presented herein indicate that, for the same replaying speed, the time needed to process the data in computer-aided time studies is likely to increase as the number of work elements and the duration of a work cycle would increase. In this study, the replaying speed has been introduced in two models as a nominal scale variable following the use of two convenient video replaying speeds.

That allowed comparisons between data 
coming from the first two experimental treatments as well as emphasizing the effect that this variable could have on the time expenditure in computer-aided data processing. Using half of the real speed added more than one minute to the time needed to process the data.

Therefore, considerable increments of time expenditure in data analysis tasks are to be expected when using lower replaying speeds as the relation between replaying speed and the replaying time when using software similar to that used herein may be expressed as a power function.

It should be mentioned here that the software used herein enables the setup of progressively doubled speeds ranging from 0.25 to 4.0 $\mathrm{x}$, where $\mathrm{x}$ represents the real speed. However, speeds greater than the real one would lead to missing some of the short duration elements as well as to inaccuracies when separating the work elements. Also, replaying speeds greater than $2.0 \mathrm{x}$ are not suitable for analyzing harvester-related data. Such speeds are more appropriate for long duration work elements such as those specific to skidding operations where some or all of the work elements have rather increased durations (cp. Borz et al. 2015, Borz et al. 2013). On the contrary, speeds of $0.25 \mathrm{x}$ unjustifiably increase the amount of time spent in processing tasks but they may be required when analyzing extremely short work elements (e.g. crosscutting very small trees). Therefore, it is likely to be used replaying speeds in range of 0.5-1.0 x, at least when analyzing detailed video data for harvesters, a fact that could support considerably the descriptive statistics and models included in this study. According to the self-evaluation of the researcher that carried out the analysis, the use of a replaying speed representing half of the real one was rather contra-productive, leading to the use on non-necessary time resources and yielding an additional fatigue. In this sense, the use of real speed combined with its reductions or increments only for those work elements requiring this procedure is more appropriate.
On the other hand, it is known that any transition to new tasks, therefore to newly organized work sequences needs accommodation for the person that should carry on the work. This fact was emphasized in forest operations as one key element affecting the time expenditure and different approaches were designed and used to balance its effects (Hiesl \& Benjamin 2013). Acknowledging that this effect would affect also the results of this study, before the effective data analysis, the researcher that was in charge of these tasks had a oneday period for accommodation purposes. As used in this study, one way to reduce the time needed for analyzing the data may reside in actually using a simple coding procedure of the work and time elements. This approach needs a familiarization of the researcher with the used codes and, depending on the number of separated work elements, it may be more or less demanding. Self time management as being specific to different researchers could affect the overall time expenditure but is less likely to apply to the models developed in this study.

On the other hand, the experience and mental flexibility of given researchers may lead to models showing dependence relations different than those presented in this study. This last effect could not be accommodated in this study but it is know that different persons would interact differently, therefore will produce different outputs when analyzing the same data. One of the examples in this direction is that reported by Nuutinen et al. (2008) who analyzed the experience effect in capturing time study data for harvesters using handhelds and who found out that inexperienced researchers are likely to miss some data concluding that the experience and skills have a strong effect in the accuracy of data. This could apply also when using procedures like those described in this study but, in this case, once missed, the work elements can be further accommodated by replaying a given portion of the video file. Of course, this would lead to increments in time expenditure 
related to data analysis, affecting this way the results included herein. In other cases the researchers fatigue and the complexity of a given work cycle may lead to additional variability.

Spinelli et al. (2013) indicated that the observer-induced variability had effects on short duration less-frequent work elements. They also pointed out that the study duration may cause fatigue and error increments. The effect of very short work elements was considered also in this study as they may require alteration of replaying speed. However, here resides the main advantage of capturing field data using video recording devices and analyzing it using professional software because this approach offers additional options such as the possibility to playback the video files and re-analyze doubtful data. By considering the above mentioned, there are some points that have to be addressed in the future. One of them is related to measuring the effects of skills, experience and mental flexibility on time expenditure in computer-aided time studies.

From statistical point of view, there is also the question on what factors triggered the increased variability in the response variable TEAt and why the dependence between the TEAt and TFPt decreased. In this direction one supporting argument would be that of variation of number of work elements that further contributed to the variability of TEAt, therefore to the small dependence as mentioned before.

Also, in a reduced number of cases, the variability induced by speed alteration and commenting procedures had to be included in the total TEAt variability, as their separation was not possible at the time the study was carried out.

This study focused on the most complex, yet achievable structure of a highly mechanized work cycle, by dividing it in a number of possible work elements that was close to the maximum. However, the resolution at which time studies are usually conducted in the applied science of forest operations may differ significantly from one study to another (Magagnotti
\& Spinelli 2012). This fact may have implications on the time expenditure in data analyzing tasks. While we tested only two replaying speeds that were somehow correlated with the speed and duration of the work elements analyzed herein, it is likely for other researchers to use higher speeds, less complicated study designs or both, facts that may lead to different results. However, the data exporting procedures are likely to be the same irrespective of the influence of other variables excepting the familiarity of the researcher with the software.

Therefore, even if indicative, under theoretical point of view, the resulted models describe the phenomena addressed in this study and, to a considerable extent, give also conclusive information on the studied aspects. As a consequence, when using similar approaches in conducting computer-aided time studies, and excepting here the time needed to setup and export or further rearrange the data inputs in a database, one should expect and allocate time resources equaling durations of at least four to six times greater than the duration of a typical work cycle, a result that should be further multiplied by the number of work cycles to be analyzed.

\section{Conclusions}

In general, our study aimed to model the relations between the time needed to analyze the video-recorded time study data and some selected independent variables for a complex analysis task that supposed the division of a work cycle into as many as identifiable work elements in the case of a highly mechanized forest equipment. This study was motivated and comes as a result of the inexistence of reported data regarding the performance in use of purposely-designed time studying software in forest operations.

Generally, our results suggest that for a given speed used to analyze and process the data using professional time studying software, 
both, the number of work elements within the analyzed work cycle as well as the effective duration of work cycles, affect the time consumption in analyzing tasks. Also, the replaying speed has a great impact on the time needed to analyze the data since using half of the real speed added more than one minute to the time needed to analyze and process one work cycle in comparison with the situation in which the real speed has been used. When using half of the real speed, the time expenditure involved by the analysis tasks was about six times greater than the mean duration of an analyzed work cycle, being significantly greater if compared to that of using the real speed which was about four times greater. On the other hand, the time needed to setup the software before the data processing tasks as well as the time needed to export the data following the completion of tasks, was less than two seconds per analyzed work cycle.

\section{Aknowledgements}

This paper is supported by the Sectorial Operational Programme Human Resources, Development (SOP HRD), ID 134378 financed from the European Social Fund and by the Romanian Government. We would like to thank to the company Aalmo AB, Sweden for providing us with a trial version of the AviX software $v$ 4.6.1. that was used in this study. We would also like to thank the reviewers of this paper for their constructive comments and suggestions that considerably helped us in improving the quality of the manuscript.

\section{References}

Acuna M., Skinnel J., Evanson T., Mitchell R., 2011. Bunching with a self-levelling feller-buncher on steep terrain for efficient yarder extraction. Croatian Journal of Forest Engineering 32(2): 521-531.

Alam M., Acuna M., Brown M., 2013. Self-levelling feller-buncher productivity based on Lidar-derived slope. Croatian Journal of Forest Engineering 34(2): 273-281.
Björheden R., Apel K., Shiba M., Thompson M., 1995. IUFRO forest work study nomenclature. Grapenberg, Sweden: Swedish University of Agricultural Science, Department of Operational Efficiency, 16p.

Borz S.A., Ignea G. Popa B., Spârchez G., Iordache E., 2015. Estimating time consumption and productivity of roundwood skidding in group shelterwood system - a case study in a broadleaved mixed stand located in reduced accessibility conditions. Croatian Journal of Forest Engineering 36(1): 137-146.

Borz S.A., Bîrda M., Ignea G., Popa B., Câmpu V.R., Iordache E., Derczeni R.A., 2014. Efficiency of a Woody 60 processor attached to a Mounty 4100 tower yarder when processing coniferous timber from thinning operations. Annals of Forest Research 57(2): 333-345. DOI: 10.15287/afr.2014.258

Borz S.A., Dinulică F., Bîrda M., Ignea G., Ciobanu V.D., Popa B., 2013. Time consumption and productivity of skidding Silver Fir (Abies alba Mill.) round wood in reduced accessibility conditions: a case study in windthrow salvage logging from Romanian Carpathians. Annals of Forest Research 56(2): 363-375.

Eisenhauer J.G., 2003. Regression through origin. Teaching statistics 25(3): 76-80. DOI: $10.1111 / 1467-$ 9639.00136

Hies1 P., Benjamin J.G., 2013. Applicability of international harvesting equipment productivity studies in Maine, USA: A literature review. Forests 4: 898-921. DOI: 10.3390/f4040898

Heinimann H.R., 2007. Forest operations engineering and management - the ways behind and ahead of a scientific discipline. Croatian Journal of Forest Engineering 28(1): 107-121.

Magagnotti N., Nati C., Picchi G., Spinelli R., 2011. Mechanized thinning of walnut plantations established on ex-arable land. Agroforestry Systems 82: 77-86. DOI: $10.1007 / \mathrm{s} 10457-010-9348-1$

Niemistö P., Korpunen H., Laurén A., Uusitalo J., 2012. Impact and productivity of harvesting while retaining young understorey spruces in final cutting of downy birch. Silva Fennica 46(1): 81-97. DOI: 10.14214/sf.67

Nurminen T., Korpunene H., Uusitalo J., 2006. Time consumption analysis of the mechanized cut-to-length harvesting system. Silva Fennica 40(2): 335-363. DOI: 10.14214/sf.346

Nuutinen Y., Väätäinen K., Heinonen J., Asikainen A., Röser D. 2008. The accuracy of manually recorded time study data for harvester operation shown via simulator screen. Silva Fennica 42(1): 63-72. DOI: 10.14214/ sf.264

Oprea I., 2008. Tehnologia exploatării lemnului [Timber Harvesting Technology]. Transilvania University Press, Braşov, 273 p.

Oprea I., Borz S.A., 2007. Organizarea şantierelor de exploatare a lemnului [Organization of Timber Harvesting Site]. Transilvania University Press, Braşov, 133 p.

Schöttl F., Lindemann U., 2015. Quantifying the complexity of socio-technical systems - a generic, interdisci- 
plinary approach. Procedia Computer Science 44: 1-10. DOI: 10.1016/j.procs.2015.03.019

Sowa J., Kulak D., Szewczyk G., 2007. Costs and efficiency of timber harvesting by NIAB 5-15 processor mounted on a farm tractor. Croatian Journal of Forest Engineering 28(2): 177-184.

Spinelli R., Laina-Rela-o R., Magagnotti N., Tolosana E., 2013. Determining observer and method effects on the accuracy of elemental time studies in forest operations. Baltic Forestry 19(2): 301-306.

Spinelli R., Nati C., 2009. A low investment fully mechanized operation for pure selection thinning of pine plan- tations. Croatian Journal of Forest Engineering 30(2): 89-97.

Strandgard M., Alam M., Mitchell R., 2014. Impact of slope on productivity of a self-levelling processor. Croatian Journal of Forest Engineering 35(2): 193-200.

Şofletea N., Curtu L., 2008. Dendrologie [Dendrology]. "Pentru Viaţă" Publishing House, Braşov, 418 p.

Visser R., Spinelli R., 2012. Determining the shape of the productivity function for mechanized felling and felling-processing. Journal of Forest Research 17: 397402. DOI: $10.1007 / \mathrm{s} 10310-011-0313-2$ 